\title{
Liver Resections for Colorectal Metastases in Patients Aged Over 75 Years
}

\author{
VLADISLAV TRESKA ${ }^{1}$, JAKUB FICHTL $^{1}$, JAN BRUHA $^{1}$, VACLAV LISKA ${ }^{1}$, \\ STANISLAV KORMUNDA ${ }^{1}$ and JINDRICH FINEK ${ }^{2}$ \\ ${ }^{1}$ Clinic of Surgery, and ${ }^{2}$ Clinic of Oncology, University Hospital, School of Medicine, Pilsen, Czech Republic
}

\begin{abstract}
Background: Concerns regarding postoperative complications following liver resection for colorectal liver metastases (CLMs) in elderly patients may lead to preference for conservative therapy. The aim of this study was to evaluate the role of patient age in the development of postoperative complications. Patients and Methods: Surgical complications were evaluated in 712 patients who underwent surgery for CLMs over the past 13 years. Seventy-two patients (10.1\%) were aged $\geq 75$ years and 640 (89.9\%) $<75$ years. The significance of the type of liver resection, preoperative American Society of Anesthesiologists classification (ASA), Child-Pugh classification,body mass index, quality of liver tissue and preoperative oncological treatment for the development of postoperative complications were evaluated. Results: We did not find any difference in the incidence of early postoperative complications between the two groups of patients. A preoperative ASA score of 3.4 $(p<0.001)$ was the principal factor for developing postoperative complications in patients aged $\geq 75$ years. Postoperative complications in patients with an ASA score of 3.4 were more frequent when the body mass index was $>26 \mathrm{~kg} / \mathrm{m}^{2}(p<0.02)$. Conclusion: Patient age does not represent a contraindication to liver resection for CLMs. An ASA score of 3 or 4 and a body mass index $>26 \mathrm{~kg} / \mathrm{m}^{2}$ are risk factors for development of early postoperative complications.
\end{abstract}

The elderly population has been expanding quite remarkably in recent years. The current life expectancy is 75-77 years for men and 80-81 years for women in industrialized

Correspondence to: Vladislav Treska, MD, Ph.D., Professor of Surgery, Clinic of Surgery, University Hospital, School of Medicine, Alej Svobody 80, 30460 Pilsen, Czech Republic. Tel: +420 377104270, Fax: +420 377103965, e-mail: treska@fnplzen.cz

Key Words: Elderly patients, colorectal liver metastases, liver resection, postoperative complications. countries. The average expected survival for a 60 -year-old is 24 years and that for an 80-year-old is 6 years. The population is aging worldwide and in developed countries the number of individuals older than 65 years is expected to reach almost $50 \%$ of the population in $2020(1,2)$.

It is very difficult to define old age and each person must be assessed strictly individually according to their age, physical and mental state, self-sufficiency etc. The World Health Organization defines several categories of old age according to the chronological age of the given individual, namely young old (60-74 years), old (75-89 years) and the period of longevity or oldest-old (over 90 years) (3).

Malignancies are in general diseases of the elderly due to the combination of an accumulation of risk factors and longterm exposure to carcinogens. It is estimated that approximately $58 \%$ of all cancers and $69 \%$ of cancer deaths in the European population occur in people aged over 75 years. The incidence of cancer is more than 11-times higher in people older than 75 years. The most commonly diagnosed cancers worldwide are lung (1.4 million), breast (1.2 million) and colorectal cancer (1 million) (4).

Colorectal liver metastases (CLMs) are a leading cause of cancer-related morbidity and mortality in the most developed countries and their incidence increases with patient age. In many studies dealing with the epidemiology of aging and CLM development, almost half of all patients with CLMs were older than 75 years (5).

Liver surgery is the only radical treatment of liver tumors that provides patients with a chance for long-term survival. However, some studies cite a high morbidity and more than $5 \%$ mortality rate for liver surgery in elderly patients $(6,7)$. Consequently, some elderly patients may be referred for less invasive or conservative oncological treatments with the expectation of better treatment results (8). The main reason for such an approach is the fear of cardiovascular, respiratory, renal, or metabolic comorbidities in elderly patients and the fact that advancing age carries with it a greater likelihood of decompensation during general anesthesia and liver surgery. 
Table I. Patients characteristics according to age group.

\begin{tabular}{|c|c|c|c|c|}
\hline \multirow[b]{2}{*}{ Characteristic } & \multirow[b]{2}{*}{ Subgroup } & \multicolumn{2}{|c|}{ Age, $n$} & \multirow[b]{2}{*}{$p$-Value* } \\
\hline & & $\geq 75$ Years $(\mathrm{N}=72)$ & $<75$ Years $(\mathrm{N}=640)$ & \\
\hline \multirow[t]{2}{*}{ Resection } & Major & 18 & 142 & 0.59 \\
\hline & Minor & 54 & 498 & \\
\hline \multirow[t]{2}{*}{ Child-Pugh class } & A & 64 & 542 & 0.34 \\
\hline & $\mathrm{B}, \mathrm{C}$ & 8 & 98 & \\
\hline \multirow[t]{2}{*}{ ASA class } & 1,2 & 19 & 373 & 0.0001 \\
\hline & 3,4 & 53 & 267 & \\
\hline \multirow[t]{2}{*}{ BMI } & $<26 \mathrm{~kg} / \mathrm{m}^{2}$ & 46 & 399 & 0.80 \\
\hline & $\geq 26 \mathrm{~kg} / \mathrm{m}^{2}$ & 26 & 241 & \\
\hline \multirow[t]{2}{*}{ Liver status } & Liver tissue injury & 8 & 108 & 0.21 \\
\hline & Normal liver tissue & 64 & 532 & \\
\hline \multicolumn{2}{|c|}{ Neoadjuvant therapy } & 9 & 70 & 0.69 \\
\hline
\end{tabular}

ASA: American Society of Anesthesiologists classification; BMI: body mass index. ${ }^{*}$ Chi-square test.

The aim of this study was to evaluate the short-term results of liver surgery (up to the 30 th postoperative day) in patients $\geq 75$ years old compared to the results in younger patients.

\section{Patients and Methods}

From January 1, 2004 until November 30, 2016, we performed liver resection for CLMs in a total of 771 patients. We were able to obtain complete data for our analysis from the charts of 712 patients, of which 72 were aged $\geq 75$ years $(10.1 \%)$ and $640(89.9 \%)$ were aged $<75$ years. The indication for liver resection was always made by a multi-disciplinary team. This involved primary liver resection in all patients. Patients with repeated resections, combined (resection with thermoablation) or staged surgical procedures were not included in our study sample. Patients who underwent more than six cycles of oncological treatment before surgery were also excluded. We gave preference to parenchymal-sparing procedures that were performed with the aid of an ultrasonic dissector (Cavitron Ultrasoniic Surgical Aspirator), harmonic scalpel and bipolar coagulation. Blood transfusions were not necessary during surgery in over $94 \%$ of patients.

We studied the following variables in both groups of patients: type of liver resection (major i.e. $\geq 3$ segments versus minor i.e. $\leq 2$ segments) according to the Couinaud classification; American Society of Anesthesiologists (ASA) preoperative classification; Child-Pugh classification (9); body mass index (BMI); quality of liver tissue according to macroscopic perioperative and postoperative sample evaluation (normal tissue versus cirrhosis, steatohepatitis, steatosis) and influence of preoperative oncological treatment. We evaluated postoperative complications according to the Clavien-Dindo classification (10).

Statistical analysis was performed usingSAS 9.3 software (Cary, NC, USA). The sample of patients was processed using multivariate logistic regression the results of which were graphically expressed using so-called classification and regression trees. The individual nodes were sought on the basis of value maximization of the test criteria of the Chi-square test of multivariate stepwise logistic regression. Different cut-off values were set for the individual continuous factors and these were subsequently tested in individual multivariate models. For categorical variables, we tested all the admissible combinations of these factors. Due to the testing of the influence of age on the presence of postoperative complications, we subsequently calculated the classification and regression trees so that the first node was firmly defined as the difference between the groups below/above 75 years, regardless of the statistical significance of the given node. The differences in selected parameters between the age groups were tested using the ChiSquare test. Statistical significance was set at the level of alpha $=5 \%$.

The study was approved by Ethics Committee of University Hospital in Pilsen, Czech Republic.

\section{Results}

In patients $\geq 75(\mathrm{~N}=72)$ and $<75(\mathrm{~N}=640)$ years of age, the values of the studied parameters are given in Table I. Minor liver resection was performed in the majority of patients ( $77.5 \%$ overall); there was no significant difference in the extent of resection between the two groups. Nor did groups differ with respect to Child-Pugh classification, BMI (using $<26 \mathrm{~kg} / \mathrm{m}^{2}$ as cut-off), state of liver health, nor in receipt or not of neoadjuvant chemotherapy. However, ASA classification differed highly significantly, with the older group more frequently being classified as ASA 3 or 4 $(p<0.0001)$.

In patients $\geq 75$ years, serious complications (ClavienDindo 3-5) occurred in $8.3 \%$ and in patients $<75$ years they occurred in $13.5 \%(p<0.12)$. Mortality within the first 30 postoperative days was $2.8 \%$ in patients $\geq 75$ years and $0.3 \%$ in patients $<75$ years $(p<0.21)$.

Patient age was not a factor that significantly affected the results of liver resection. If a complication occurred in patients $\geq 75$ years, then it was associated in the second node of the classification and regression tree with a preoperative 


\section{CLASSIFICATION AND REGRESSION TREE \\ First node: age cut off 75 years (not statistically significant) Endpoint: complication NO vs. YES}

Complication $=$ NO Complication $=$ YES Complication probability p-Value (Chi-square)

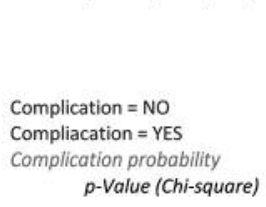
Complication $=$ YES Complication probability p-Value (Chi-square)

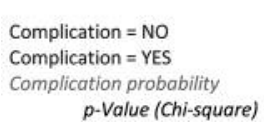

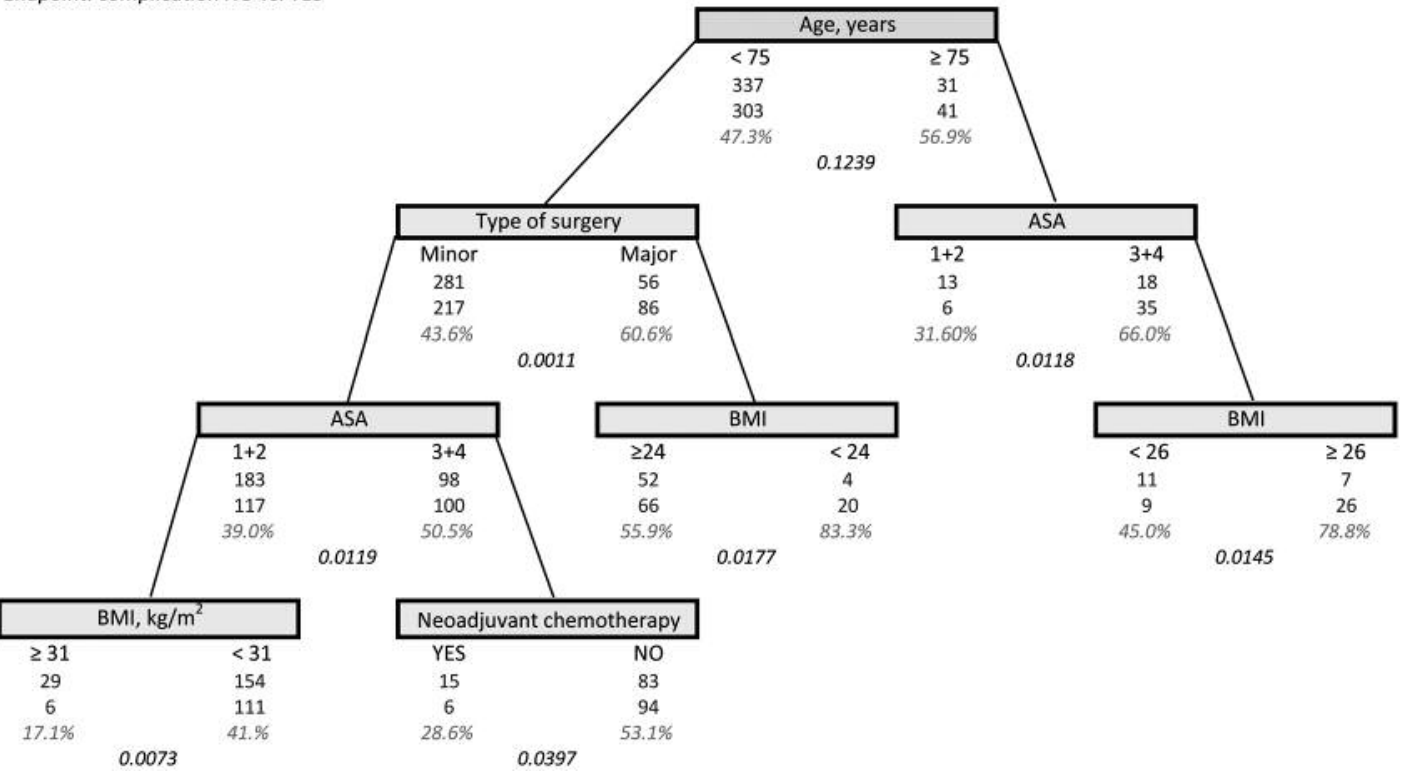

Figure 1. Classification and regression tree of postoperative complications according to patient age.

ASA score of 3 or $4(p<0.01)$ and in the third node with a BMI of $26 \mathrm{~kg} / \mathrm{m}^{2}$ or more $(p<0.02)$. Thus, patients aged 75 years or more with ASA 3 or 4 and a BMI of $26 \mathrm{~kg} / \mathrm{m}^{2}$ or more represented a group at risk of complications. The other variables studied with regards to the incidence of postoperative complications were not significant in this group of patients (Figure 1).

\section{Discussion}

Recent data clearly indicate that the number of people over the age of 75 years is increasing, accounting for approximately $15 \%$ of the total population. We can expect the number of elderly patients to further increase in the near future. The problem of patient aging not only lies in the increasing incidence of malignancies, including liver tumors, but also in the significantly increasing incidence of comorbidities.

Radical liver resection is the gold standard for the treatment of CLMs, providing the best long-term results. The 5 -year overall survival rate after radical liver resection is between 35 and $60 \%$ according to our personal experience and literature data $(11,12)$. Untreated patients with CLMs rarely survive longer than 1 year. Patients treated using solely modern oncological therapy without liver surgery have an expected maimed survival of 22-24 months. The 30-day mortality rate for patients undergoing liver resection at specialized hepatobiliary centers is below $3 \%$ due to the use of advanced resection techniques and to modern trends in anesthesiology and intensive care $(13,14)$.

Accurate preoperative diagnosis is extremely important in elderly patients, who often suffer from various concomitant diseases. In our group of patients aged 75 years or more, there was a significant proportion of high-risk patients (ASA $3,4)$, which in turn had a prognostic effect on the development of serious (Clavien-Dindo 3-5) postoperative complications. The other risk factor for developing immediate postoperative complications in patients $\geq 75$ years included having a high BMI $(p<0.02)$, which is understandably related to the generally rising incidence of excess weight in the population and the associated higher incidence of wound infection and cardiopulmonary complications.

Careful preoperative evaluation of the overall patient health status is very important before major liver surgery, especially in elderly patients. Evaluation of cardiopulmonary status (standard chest X-ray, electrocardiogram, echocardiography with estimation of ventricular kinetics and ejection fraction), renal function and complete blood chemistry tests should be performed during the basic examination of patients $\geq 75$ years old. In the case of a positive medical history of coronary artery disease, additional cardiovascular examination is indicated. Preoperative assessment of the functional, cognitive and emotional status of elderly patients is also very important $(15,16)$. 
Special pathophysiological considerations must also be taken into consideration when treating elderly patients. During aging, the liver undergoes physiological changes, resulting in decreased size and reduced blood flow (by as much as $45 \%$ in octogenarians). The number of hepatocytes is also reduced and hepatocyte morphology and function deteriorate. The functional reserve of the liver and its regenerative capacity are diminished. The synthesis of proteins and clotting factors may be impaired. The acute-phase protein response is also inhibited. The inhibition of this response can be the cause of a greater incidence of postoperative infection in elderly patients $(17,18)$. Postoperative hepatic failure following liver resection also occurs more frequently in elderly patients (19, 20). Therefore, liver cirrhosis (Child-Pugh stages B and C) and other conditions associated with seriously deteriorated liver function are contraindications for major hepatic resection. We recommend assessing liver function [e.g. indocyanine green (ICG) retention test] in all patients over 70 years of age before performing major liver surgery. If the retention rate after 15 minutes of intravenous ICG application is less than $14 \%$, the tolerance of major hepatectomy is good. If the retention rate is greater than $20 \%$, the patient should not undergo major liver surgery. If the retention rate is between $14-20 \%$, the patient can undergo liver surgery if the future remnant liver volume (FRLV) is more than 50\%. The FRLV is another very important factor for safe surgery in elderly patients. If the FRLV is lower than $20 \%$ for healthy liver tissue, lower than $30 \%$ after extensive chemotherapy (more than six cycles), or lower than $40 \%$ in patients with cirrhosis, then methods that increase the FRLV are indicated. In the elderly population, these most often involve portal vein embolization $(21,22)$. Because of our adhering to this policy, we have experienced zero liver insufficiency in our group of elderly patients and a rate of only $0.4 \%$ in our group of younger patients.

The important changes in surgical techniques of liver resection over the past 20 years represent another critical factor for the reduced incidence of postoperative complications in general, and in patients over the age of 75 years in particular. Liver resection techniques have changed quite importantly from those involving significant blood loss, such as the finger-fracture or Kelly fracture techniques, to organ-sparing liver dissection using ultrasonic dissection devices, argon lasers, bipolar electrocoagulation devices, harmonic scalpels, water-jet dissectors, etc. Blood transfusions are no longer necessary in most patients undergoing major liver resection. Current techniques for liver surgery involve liver-sparing procedures, emphasizing on radical procedures with margin-negative $\mathrm{R} 0$ resections $(23,24)$. During parenchymal transection, we use either intermittent complete liver ischemia (Pringles maneuver for 15-20 minutes with 5-10 minutes of reperfusion) or selective liver ischemia (extrahepatic ligation or clip application).
Resectable extrahepatic metastases (e.g. lung, nodular metastases, peritoneal implants) are not contraindications for liver surgery in elderly patients, if they can be radically removed (25). Their surgical removal does not increase morbidity nor mortality in older patients (26). Moreover, repeated liver resections are not contraindicated in patients $\geq 75$ years old who are in good condition, and can be performed with acceptable morbidity and mortality rates that are very similar to those for primary liver surgery $(27,28)$.

A drawback of this study is its retrospective design and the fact that we evaluated the significance of major resection procedures in relation to immediate postoperative complications in patients older than 75 years. In this group of patients, there were only 18 cases of major liver resection. This is not comparable to the number of major resections in patients younger than 75 years. Undoubtedly, a larger sample of operated older patients will be needed in order to accurately assess the influence of major liver resection on the immediate postoperative complications. Nonetheless, we may state that liver resection of CLMs in patients over the age of 75 years represents a safe method from which patients may profit therapeutically. The precondition for an uncomplicated postoperative course in such patients is the correct indication for surgery within a multidisciplinary team, taking into consideration not only the resectability of the CLMs but also mainly the patient's health status based on an assessment of comorbidities and BMI in relation to their quality of life after liver resection.

\section{Acknowledgements}

This study was supported by the Charles University Research Fund (PROGRES).

\section{References}

1 Rozzini R: Aging clinical problems: a difficult balance between age and frailty. Monaldi Arch Chest Dis 22: 727-732, 2016.

2 Nachmany I, Pencovich N, Zohar N, Goykhman Y, Lubezky N, Nakache R and Klausner JM: Resection of colorectal liver metastases in the elderly - Is it justified? J Surg Oncol 113: 485488, 2016.

3 Huisman M, Read S, Towriss CA, Deeg DJ and Grundy E: Socioeconomic inequalities in mortality rates in old age in the World Health Organization Europe region. Epidemiol Rev 35: 84-97, 2013.

4 Hanson HA1, Smith KR, Stroup AM and Harrell CJ: An ageperiod-cohort analysis of cancer incidence among the oldest old, Utah 1973-2002. Popul Stud 69: 7-22, 2015.

5 Kavlakoglu B, Ustun I, Oksuz O, Pekcici R, Ergocen S and Oral S: Surgical treatment of liver metastases from colorectal cancer: Experience of a single institution. Arch Iran Med 14: 120-125, 2011.

6 Menon KV, Al-Mukhtar A, Aldouri A, Prasad RK, Lodge PA and Toogood GJ: Outcomes after major hepatectomy in elderly patients. J Am Coll Surg 203: 677-683, 2006. 
7 de Liguori Carino N, van Leeuwen BL, Ghaneh P, Wu A, Audisio RA and Poston GJ: Liver resection for colorectal liver metastases in older patients. Crit Rev Oncol Hematol 67: 273278, 2008

8 Yazici P, Akyuz M, Yigitbas H, Dural C, Okoh A, Aydin N and Berber E: A comparison of perioperative outcomes in elderly patients with malignant liver tumors undergoing laparoscopic liver resection versus radiofrequency ablation. Surg Endosc, 2016. doi: 10.1007/s00464-016-5105-5

9 Theivanayagam S, Lopez KT, Matteson-Kome ML, Bechtold ML and Asombang AW: ASA Classification pre-endoscopic procedures: a retrospective analysis on the accuracy of gastroenterologists. South Med J 110: 79-82, 2017.

10 Hijazi Y, Gondal U and Aziz O: A systematic review of prehabilitation programs in abdominal cancer surgery. Int J Surg 39: 156-162, 2017.

11 Grande R, Natoli C, Ciancola F, Gemma D, Pellegrino A, Pavese I, Garufi C, Di Lauro L, Corsi D, Signorelli D, Sperduti I, Cortese G, Risi E, Morano F, Sergi D, Signorelli C, Ruggeri EM, Zampa G, Russano M and Gamucci T: Treatment of metastatic colorectal cancer patients $\geq 75$ years old in clinical practice: a multicenter analysis. PLOS Medicine 11: e0157751, 2016.

12 Primrose JN: Surgery for colorectal liver metastases. Br J Cancer 102: 1313-1318, 2010.

13 Pope D, Ramesh H, Gennari R, Corsini G, Maffezzini M, Hoekstra HJ, Mobarak D, Sunouchi K, Stotter A, West C and Audisio RA: Pre-operative assessment of cancer in the elderly (PACE): A comprehensive assessment of underlying characteristics of elderly cancer patients prior to elective surgery. Surg Oncol 15: 189-197, 2007.

14 Ettorre GM, Sommacale D and Farges O: Postoperative liver function after elective right hepatectomy in elderly patients. $\mathrm{Br}$ J Surg 88: 73-76, 2001.

15 Menon KV, Al Mukhtar A and Aldouri A: Outcomes after major hepatectomy in elderly patients. J Am Coll Surg 203: 677-683, 2006.

16 Aldrighetti L, Arru M, Calori G, Caterini R, Comotti L, Torri G and Ferla G: Impact of age on the outcome of liver resections. Am Surg 70: 453-460, 2004.

17 Grundmann RT: Current state of surgical treatment of liver metastases from colorectal cancer. World J Gastrointest Surg 12: 183-196, 2011.

18 Ismaili N: Treatment of colorectal liver metastases. World J Surg Oncol 9: 154, 2011.
19 Rocha FG and Helton WS: Resectability of colorectal liver metastases: an evolving definition. HPB 14: 283-284, 2012.

20 Cannistrà $\mathrm{M}$, Grande R, Ruggiero $\mathrm{M}$, Novello $\mathrm{M}$, Zullo A, Bonaiuto E, Vaccarisi S, Cavallari G, Serra R and Nardo B: Resection of hepatocellular carcinoma in elderly patients and the role of energy balance. Int J Surg 33: 119-125, 2016.

21 Treska V, Topolcan O, Vrzalova J, Skalicky T, Sutnar A, Liska V, Fichtl J, Narsanska A, Ferda J, Treskova I, Mirka H and Kreuzberg B: Predictive value of serum biomarkers in patients after portal vein embolization (PVE): a pilot study. Anticancer Res 31: 339-344, 2011.

22 Ribero D, Abdalla EK and Madoff DC: Portal vein embolization before major hepatectomy and its effects on regeneration, resectability and outcome. Br J Surg 11: 1386-1394, 2007.

23 Clavien PA, Petrowsky H, DeOliveira ML and Graf R: Strategies for safer liver surgery and partial liver transplantation. N Engl J Med 356: 1545-1559, 2007.

24 Orcutt ST, Artinyan A, Li LT, Silberfein EJ, Berger DH, Albo D and Anaya DA: Postoperative mortality and need for transitional care following liver resection for metastatic disease in elderly patients: a population-level analysis of 4026 patients. HPB 14: 863-870, 2012.

25 Vladov N, Vasilevski I, Takorov I, Mutafchiyski V, Sergeev S, Odiseeva $\mathrm{E}$ and Katzarov K: Rational surgical aggression in multimodal treatment of liver colorectal metastases. HepatoGastroenterology 59: 241-244, 2012.

26 Treska V, Skalicky T, Liska V, Sutnar A, Ferda J, Mirka H, Slauf F, Kreuzberg B and Fichtl J: Prognostic value of the number and volume of liver tumours on portal vein embolization outcomes. Hepato Gastroenterology 59: 448-452, 2012.

27 Nardo B, Serafini S, Ruggiero M, Grande R, Fugetto F, Zullo A, Novello M, Rizzuto A, Bonaiuto E, Vaccarisi S, Cavallari G, Serra R, Cannistrà $\mathrm{M}$ and Sacco $\mathrm{R}$ : Liver resection for metastases from colorectal cancer in very elderly patients: New surgical horizons. Int J Surg 33: 135-141, 2016.

28 Aldrighetti L, Arru M, Catena M, Finazzi R and Ferla G: Liver resections in over-75-year-old patients: Surgical hazard or current practice? J Surg Oncol 93: 186-193, 2006.

Received January 3, 2017

Revised February 11, 2017

Accepted February 15, 2017 